\title{
Effectiveness Of 1.2\% Simvastatin Gel as an Adjunct to Non-Surgical Therapy in The Treatment of Chronic Periodontitis: A Split Mouth Randomized Controlled Trial
}

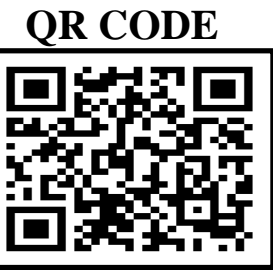

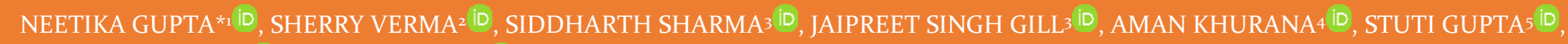
TAUQEER-UL-NISA ${ }^{10}$, ARUSHI DEWAN ${ }^{1}$ iD

BACKGROUND: Periodontitis is an inflammatory disease that results in bone resorption creating bony defects, which may cause tooth loss.

AIM: The present study aimed to evaluate the effectiveness of $1.2 \%$ Simvastatin gel as an adjunct to non-surgical therapy to treat chronic periodontitis $(\mathrm{CP})$.

MATERIALS AND METHOD: 25 patients with 50 sites were categorized into two treatment groups: scaling and root laning plus $1.2 \%$ Simvastatin, and Scaling and Root Planing with placebo. Clinical parameters; site-specific plaque index, modified sulcus bleeding index (mSBI), pocket probing depth (PD), and relative attachment level (RAL) were recorded at baseline, 3, 6, and 9 months.

RESULTS: Mean PD reduction and mean RAL gain was found to be greater in Simvastatin group than the placebo group, at 3, 6, and 9 months. CONCLUSION: Locally delivered Simvastatin was found to be effective in the treatment of Chronic Periodontitis (CP).

KEYWORDS: Simvastatin, Local Drug Delivery, Chronic Periodontitis, Inflammation, Statins

\begin{abstract}
INTRODUCTION
Periodontitis is a chronic infectious disease of the supporting tissues of the teeth. Bacterial infection can cause periodontal tissues to become inflamed and eventually destroyed by the inflammatory process. If we do not treat the disease, teeth lose their ligamentous support to the alveolar bone. Once the alveolar bone is resorbed, the teeth become mobile and are eventually lost. ${ }^{1}$ In almost all types of periodontitis, both the oral microflora and the human response play significant purpose in the commencement and progression of these diseases.
\end{abstract}

Use of adjunctive various host-modulating agents like non-steroidal anti-inflammatory drugs, subantimicrobial dose doxycycline, bisphosphonates, selective estrogen receptor modulators, resolvins, lipoxins, to mention a few, are estimated. More recently, statins, which are hypolipidemic drugs of choice, are being explored as anti-inflammatory and osteoinductive agents. The anti-inflammatory effects that are postulated to provide cardioprotective benefits beyond those attributable to the hypolipidemic effects alone are referred to as pleiotropic effects. ${ }^{2}$

5-hydroxymethylglutaryl-CoA reductase inhibitors, usually referred to as statins, decrease cholesterol levels by inhibiting cholesterol biosynthesis. This will, in turn, reduce the chances of cardio-vascular issues, as do other drugs that reduce the cholesterol levels in serum. Their activity essentially consists of competitively inhibiting 3-hydroxy-3 methyl glutaryl co-enzyme A reductase (HMG CoA) that will inhibit cholesterol synthesis. It is evident that statins exert several vascular actions that are not lipid lowering. ${ }^{3}$ Statins have proven to have significant anti-oxidative and anti- inflammatory properties. ${ }^{4}$

It has pleiotropic effects and anti-Inflammatory property, that is associated with the reduction in isoprenoids that is accountable for post-translational modification of proteins. ${ }^{5}$ Among these proteins, the reduced prenylation and small G-proteins activity (Ras, Rho) appears significant. At a minimum, the effects include a reduced inflammation in vessels by inhibiting the macrophage activation and proliferation; inhibition of secretion of MMP- matrix metallo-proteinases; inhibition of smooth vascular muscle proliferation and platelet activation; promotion of neovascularization through direct angiogenesis or mobilization of endothelial progenitor cells; antioxidant effect through downregulation of angiotensin 1 receptor expression and inhibition of Nicotinamide Adenine Dinucleotide Phosphate (NADPH) oxidase activity. ${ }^{6,7}$

The protective cardiovascular effect partly comes from anti-inflammatory property such as Inhibiting TNF-a and MMP-9. MMP-9 and TNF-alpha are responsible for tissue destruction in chronic periodontitis. Moreover, statins are believed to increase bone formation 
by stimulating the bone morphogenetic protein-2 production. ${ }^{8}$ Hence, it seems possible that statins might be protective against cardiovascular problems and chronic periodontitis. Various animal studies showed Simvastatin (SMV) aids in bone regeneration and shows anti-inflammatory effect when delivered or applied locally. ${ }^{9}$

Our study has been designed to assess the efficacy of locally delivered drug of Simvastatin 1.2\% into the deep periodontal pocket stimulating a substantial increase in pocket probing depth (PPD) reduction, relative clinical attachment level (CAL) gain as compared to the placebo gel as an adjunct to (SRP) scaling and root planing in the management of Periodontitis.

\section{MATERIALS AND METHODS}

Source of data: The investigation was a comparative assessment of the efficiency of an indigenously developed Locally Delivered Drug (LDD) simvastatin conducted out in the Department of Periodontics, in ITS Dental College. After ethical approval was given, written informed consent was signed by all study participants. The study was carried out from January 2018 to December 2018.

Formulation and in vitro evaluation of gels containing simvastatin: Methylcellulose in situ gel was prepared by adding biocompatible solvent to the appropriate amount of methylcellulose. The solution was heated to $50-60{ }^{\circ} \mathrm{C}$ and then agitated with mechanical shaker in order to get a clear solution. A pre- determined amount of Simvastatin was poured to the solution and then dissolved fully. A homogeneous phase of polymer, solvent, and drug. A 1.2\% SMV insitu gel was ready.

Local Drug Delivery: For standardization, $10 \mathrm{~mL}$ prepared SMV gel (1.2 $\mathrm{mg} /$ o.1 $\mathrm{mL}$ ) was injected into the pockets using a syringe with a blunt cannula) (figure 2). Patients were directed to abstain from chewing hard or sticky foods, brushing near the treated areas or using any interdental aids for one week. Adverse effects were noted at recall visits, each patient was reinstructed for proper oral hygiene procedures at recall visits, where any supragingival deposits were removed.

Selection Criteria: Patients with $\mathrm{PD} \pm 5 \mathrm{~mm}$ or relative $\mathrm{CAL} \pm 4 \mathrm{~mm}$ with no history of periodontal therapy or use of antibiotics in the last 6 months, with presence of atleast 20 teeth, were included. The periodontal

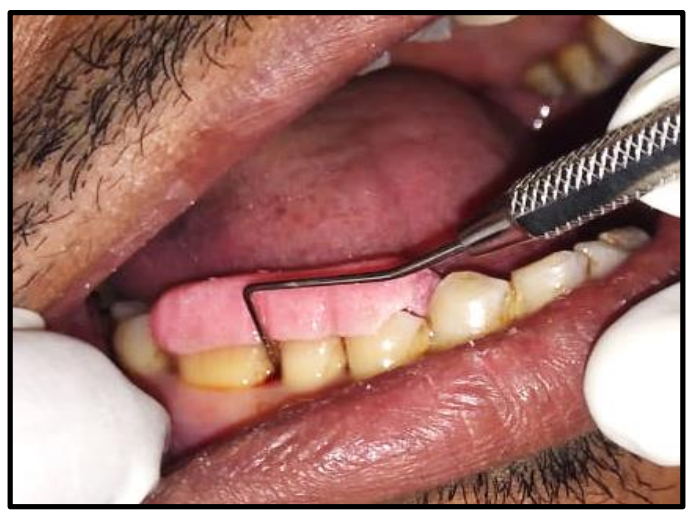

Figure 1. Pre-Operative Records of Indices and Clinical Parameters

parameters were assessed at six sites per tooth using a periodontal probe. Individuals with known systemic disease, patients with known or suspected allergy to the Simvastatin, those on systemic Simvastatin therapy, individuals with hyperlipidemia or individuals who process a lipid-reducing diet, individuals with Aggressive periodontitis, patients who use tobacco, alcoholics, immunocompromised individuals, and pregnant or lactating females were not included in the study. Also, teeth with furcation defects, gingival recession, endodontic (pulpal) involvement, and third molars were excluded.

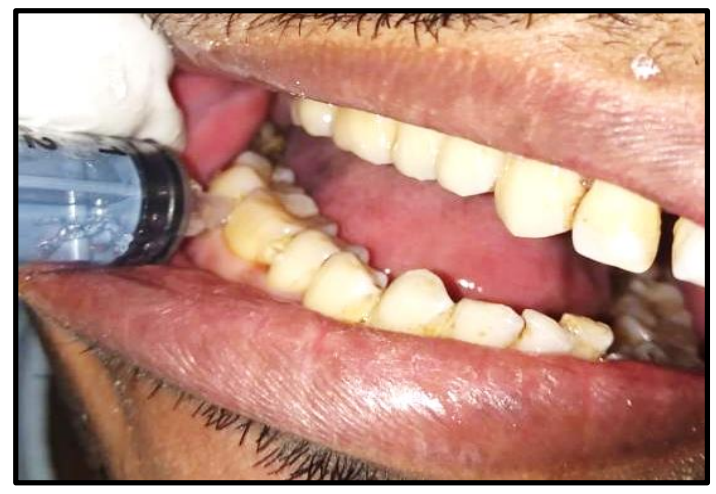

Figure 2. Local Drug Delivery - $1.2 \%$ Simvastatin in the Pocket after SRP

25 patients were able to fit in the inclusion criteria with 50 sites. All the parameters- site specific plaque index, modified sulcular bleeding index, pocket probing depth, relative attachment level were checked at baseline. (figure 1). Random allotment was done using the coin toss method, and groups were assigned. Group 1 was the control Group, where the scaling and root planing were done along with placebo gel placement. Group 2 included patients where along with scaling and 
root planing, $1.2 \%$ Simvastatin gel was placed. COE pack was placed for 1 week. All the parameters were rechecked at 3 months and 6 months (figure 3).

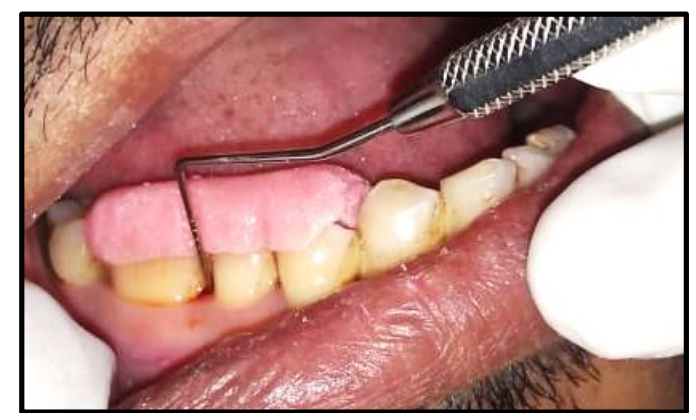

Figure 3. Recoding of All the Parameters At 3 Months, And 6 Months

Statistical Analysis: Statistical investigation of the data was carried out using Statistical Package for the Social Sciences (SPSS) software 16. Student's paired ttest was applied to test the mean changes in scores at different time points within each study group. (ANOVA) One-way analysis of variance was carried out to compare the mean scores between different study groups. Tukey's "honestly significant difference" procedure was carried out to identify the significant groups if the test of significance in one-way ANOVA was significant. $\mathrm{P}<0.05$ was considered as the level of significance in this study.

\section{RESULT}

Twenty-five (two sites per participant) subjects were able to complete the study (table 1) All participants accepted the drug very well with no complications or adverse reactions to the drug. Soft tissues healed uneventfully, and no major visual differences were noted.

The two groups revealed improvement in site-specific PI score, but there wasn't statistical substantial difference in site-specific PI score among the 2 groups at any visit (tables $1 \& 2$ ). This specifies that both the groups kept comparable levels of dental hygiene during the study. mSBI in the both groups showed no difference at baseline, but it was considerably reduced in the SMV group compared with placebo group at 3 and 6 months $(\mathrm{P}<0.05)$ (table 1$)$. Clinical parameters(PPD) pocket probing depth and relative CAL also showed no substantial difference between the 2 groups at baseline. However, the SMV group showed significantly greater PD pocket depth reduction and

\begin{tabular}{|c|c|c|c|}
\hline VARIABLE & $\begin{array}{c}\text { GROUP } \\
1(\mathrm{~N}=10)\end{array}$ & $\begin{array}{c}\text { GROUP } \\
2(\mathrm{~N}=10)\end{array}$ & $\begin{array}{c}\text { P- } \\
\text { VALUE }\end{array}$ \\
\hline Age (year) & $\begin{array}{c}32.50 \pm \\
8.182\end{array}$ & $\begin{array}{c}32.50 \pm \\
8.121\end{array}$ & 1.000 \\
\hline $\begin{array}{c}\text { Site specific } \\
\text { Plaque index }\end{array}$ & $\begin{array}{c}2.8 \pm \\
0.2261\end{array}$ & $\begin{array}{c}2.14 \pm \\
0.1845\end{array}$ & 0.634 \\
\hline $\begin{array}{c}\text { Modified } \\
\text { sulcular } \\
\text { bleeding } \\
\text { index }\end{array}$ & $\begin{array}{c}1.31 \pm \\
1080\end{array}$ & $\begin{array}{c}1.37 \pm \\
0.1287\end{array}$ & 0.465 \\
\hline $\begin{array}{c}\text { Probing } \\
\text { depth }\end{array}$ & $5.20 \pm$ & $5.40 \pm$ & 0.645 \\
\hline $\begin{array}{c}\text { Relative } \\
\text { attachment }\end{array}$ & 0.516 & 0.445 & \\
level & 0.675 & $0.90 \pm$ & 0.543 \\
\hline
\end{tabular}

Table 1. Subjects and their periodontal defect characteristics at baseline [Values are presented as mean \pm SD; Group 1: Control site: SRP was performed, with placement of placebo gel; Group 2: Test site: SRP was performed with placement of $1.2 \%$ Simvastatin gel in the pockets.]

relative CAL gain at 3 and 6 months compared to the control group at $\mathrm{P}<0.001$ (table 3 ).

\section{DISCUSSION}

Our present research evaluated the clinical efficiency of $1.2 \%$ SMV in- situ gel in adjunctive measure to SRP (scaling and root planing) in treatment of patients with $\mathrm{CP}$ and showed substantial enhancement in parameters compared to the placebo gel. There are very few studies recording the use of $1.2 \%$ SMV gel as local drug delivery to treat patients with periodontitis. Therefore, a straightforward comparison with other studies is not practical.

The mean site-specific plaque index in the group -1 (control group at baseline was $2.8 \pm 0.2261 \mathrm{~mm}$, after 3months was $1.35 \pm 0.1945 \mathrm{~mm}$, and $1.30 \pm 0.1945 \mathrm{~mm}$ after 6 months. The mean reduction in site-specific plaque index from the baseline to 3 month and 6 months was statistically significant in our control group. The mean site-specific plaque index at baseline was $2.14 \pm 0.1845$ $\mathrm{mm}$, after 3 months was $1.18 \pm 0.1370 \mathrm{~mm}$, and $1.05 \pm 0.1347 \mathrm{~mm}$ after 6 months in the test group. The test group showed a statistically significant mean reduction in site-specific plaque index from baseline to 3 and 6 months. The site-specific plaque index of both groups reduced throughout the time intervals. However, the SMV group displayed a more substantial reduction in the site-specific plaque index in the test group than the control group (Group-1) upon 


\begin{tabular}{|c|c|c|c|c|c|c|c|c|}
\hline & VARIABLE & BASELINE & $\begin{array}{c}3 \\
\text { MONTHS }\end{array}$ & 6-MONTH & $\begin{array}{c}\text { BASELINE -3 } \\
\text { MONTHS } \\
\text { DIFFERENCE }\end{array}$ & $\begin{array}{c}\text { p- }^{-} \\
\text {VALUE }\end{array}$ & $\begin{array}{l}\text { BASELINE -6 } \\
\text { MONTHS } \\
\text { DIFFERENCE }\end{array}$ & $\begin{array}{c}\text { p- }^{-} \\
\text {VALUE }\end{array}$ \\
\hline \multirow{3}{*}{$\begin{array}{l}\text { Plaque } \\
\text { Index }\end{array}$} & GROUP 1 & $2.8 \pm 0.2261$ & $1.35 \pm 0.1945$ & $1.30 \pm 0.1945$ & $1.45 \pm 0.031$ & 0.0045 & $1.5 \pm 0.195$ & 0.0048 \\
\hline & GROUP 2 & $2.14 \pm 0.1845$ & $1.18 \pm 0.1370$ & $1.05 \pm 0.1347$ & $0.96 \pm 0.047$ & 0.0023 & $1.09 \pm 0.137$ & 0.0032 \\
\hline & $\mathrm{p}$-value & 0.634 & & & 0.0036 & & 0.0043 & \\
\hline \multirow{3}{*}{$\begin{array}{l}\text { Modified } \\
\text { Bleeding } \\
\text { Index }\end{array}$} & GROUP $_{1}$ & $1.31 \pm 0.1080$ & $1.16 \pm 0.0589$ & $1.03 \pm 0.0876$ & $0.15 \pm 0.049$ & 0.0042 & $1.16 \pm .020$ & 0.0045 \\
\hline & GROUP 2 & $1.37 \pm 0.1287$ & $0.73 \pm 0.1566$ & $0.57 \pm 0.1703$ & $0.64 \pm 0.027$ & 0.0024 & $0.8 \pm 0.111$ & 0.00324 \\
\hline & $p$-value & 0.465 & & & 0.0032 & & $0 . .003$ & \\
\hline
\end{tabular}

Table 2. Plaque Index and Modified Bleeding Index scores at baseline, 3 months and 6-month after SRP. [Values are presented as mean $\pm \mathrm{SD}$ ]

intergroup comparison.

In the control group, the mean modified sulcular bleeding index at baseline was $1.31 \pm 0.1080 \mathrm{~mm}$. After 3 months it was $1.16 \pm 0.0589 \mathrm{~mm}$ and after 6 months was $1.03 \pm 0.0876 \mathrm{~mm}$. The control group showed substantial reduction in mean modified sulcular bleeding index from baseline to 3 months, and then to 6 months. In the test group, the mean modified sulcular bleeding index at baseline was $1.37 \pm 0.1287 \mathrm{~mm}$. After 3 months it was $0.73 \pm 0.1566 \mathrm{~mm}$ and after 6 months, $0.57 \pm 0.1703$ $\mathrm{mm}$. A statistically substantial mean reduction occurred in the test group's modified sulcular bleeding index from baseline to 3 and 6 months. A decrease in the mean modified sulcular bleeding index was noted in both groups from baseline to the different time intervals. However, the SMV group displayed a more significant reduction in the mean modified sulcular bleeding index in the test group than the control group on the intergroup comparison.

In our present study - group 1 (control group), the mean Pocket Probing Depth (PPD) at baseline was $5.20 \pm 0.516 \mathrm{~mm}$. After 3 months it was $3.80 \pm 0.542 \mathrm{~mm}$ and after 6 months was $3.70 \pm .583 \mathrm{~mm}$. The control group showed a statistically significant mean reduction in mean pocket probing depth from baseline to 3 months and 6 months. The test group showed a mean pocket probing depth at baseline of $5.40 \pm 0.445 \mathrm{~mm}$. After 3 months it was $3.20 \pm 0.243 \mathrm{~mm}$ and after 6 months it was $2.84 \pm .766 \mathrm{~mm}$. The test group displayed a statistically significant mean reduction of pocket probing depths from baseline throughout our specified time intervals. A decline in the mean pocket probing depths were recorded in both groups from baseline to till both the time intervals. However, the SMV group displayed a more substantial reduction in the test group than the control group on the intergroup comparison.
In the control group, the mean relative (rCAL) clinical attachment level at baseline was $08.70 \pm 0.675 \mathrm{~mm}$. Subsequently 3 months later it was $7.20 \pm 0.632 \mathrm{~mm}$ and after 6 months it was $6.84 \pm 0.223 \mathrm{~mm}$. The control group showed a significant change in mean relative clinical attachment level from baseline to 3 and 6 months. The mean (rCAL) relative clinical attachment level in the test group at baseline was $08.90 \pm 0.756 \mathrm{~mm}$. 3 months later, it was $6.90 \pm 0.483 \mathrm{~mm}$ and after 6 months it was $6.63 \pm 0.236 \mathrm{~mm}$. The Group 2 showed statistically substantial changes in the mean (rCAL) relative clinical attachment level from baseline to 3 and 6 months. A reduction in the (rCAL)relative clinical attachment level have been noted in 2 groups from baseline to the different time intervals. However, the SMV group displayed a more significant reduction in the test group than the control group on the intergroup comparison.

The test group - 2 shows a more drastic decrease in indices, (PPD) pocket probing depth, and (Rcal) relative attachment level than the control group. The gingival bleeding index reduced from baseline to 6 months, suggesting that simvastatin has an antiinflammatory effect. A comparable anti-inflammatory effect of SMV was noted by Lindy et al. ${ }^{10}$ in patients with chronic periodontitis on systemic statin therapy. The patients taking statins had $37 \%$ fewer periodontal pockets than those not taking statin medication. Sakoda et al." demonstrated the anti-inflammatory effect of SMV on oral epithelium cells, evidently involving Racı guanosine triphosphatase inhibition, and noted reduced IL- 6 and IL-8 production. However, the scores of PI were also lower for both the respective groups. Considering that both groups had better plaque control (table 2), any reduction of gingival bleeding may be attributable to the better plaque control only and not by using the SMV. 


\begin{tabular}{|c|c|c|c|c|c|c|c|c|}
\hline & Variable & Baseline & 3 Months & 6-Month & $\begin{array}{c}\text { Baseline -3 } \\
\text { Months } \\
\text { Difference }\end{array}$ & $\begin{array}{c}\mathbf{P} \\
\text { Value }\end{array}$ & $\begin{array}{c}\text { Baseline -6 } \\
\text { Months } \\
\text { Difference }\end{array}$ & P-Value \\
\hline \multirow{3}{*}{$\begin{array}{l}\text { Pocket } \\
\text { Probing } \\
\text { Depth }\end{array}$} & GROUP $_{1}$ & $5.20 \pm 0.516$ & $3.80 \pm 0.542$ & $3.70 \pm .583$ & $1.40 \pm 0.026$ & 0.048 & $1.5 \pm 0.067$ & 0.0049 \\
\hline & $\begin{array}{c}\text { GROUP } \\
\mathbf{2}\end{array}$ & $5.40 \pm 0.445$ & $3.20 \pm 0.243$ & $2.84 \pm .766$ & $2.20 \pm 0.202$ & 0.032 & $2.56 \pm 0.245$ & 0.0036 \\
\hline & $P$-value & 0.645 & & & 0.0038 & & 0.0048 & \\
\hline \multirow{3}{*}{$\begin{array}{c}\text { Relative } \\
\text { Attachment } \\
\text { Level }\end{array}$} & GROUP $_{1}$ & $08.70 \pm 0.675$ & $7.20 \pm 0.632$ & $6.84 \pm 0.223$ & $1.5 \pm 0.043$ & & $1.86 \pm 0.45$ & 0.048 \\
\hline & $\begin{array}{c}\text { GROUP } \\
\mathbf{2}\end{array}$ & $08.90 \pm 0.756$ & $6.90 \pm 0.483$ & $6.63 \pm 0.236$ & $2.00 \pm 0.273$ & & $2.27 \pm 0.48$ & 0.032 \\
\hline & $P$-value & 0.543 & & & 0.0032 & & 0.0045 & \\
\hline
\end{tabular}

Table 3. Clinical parameters: Pocket Probing Depth and Relative Attachment Level at baseline, 3 months and 6-month after SRP

Similarly, PPD reduction was significant from baseline to 6 months and substantial difference among all groups at any interval of time. The reduction in the RALs at the end of the 6 month period was statistically relevant for the test groups and a less significant reduction for the control group, suggesting a more consistent outcome with statins, even though there is a noticeable difference among the three groups at any stage. Similar effects were recorded in the studies by Thorat and Pradeep ${ }^{12,13}$ and Rao et al. ${ }^{14}$, who reported significant favorable alterations in the PPD and attachment levels in the Group -2 in contrast with the control group.

The sound effects of SRP are profound about clinical improvement and microbial suppression that the remaining dynamic range of disease expression or margin for additional clinical improvement is too small to measure the effects of any additional therapy. Thus, using anti-inflammatory drugs adjunctively to debridement therapy is ill-advised from an experimental design standpoint. ${ }^{2}$ Although this combined therapy may ultimately be preferred for those who possess a hyper-inflammatory phenotype, it is not ideal from a regulatory or drug development standpoint. Logically, this places the timing for such drugs either before the disease develops, as a preventive measure, or after debridement. Research has proved the dual relationship between periodontal disease and hyperlipidemia. It may very well prove that systemic disease can predispose to an oral infection, and once this oral infection is significant, it can exacerbate the systemic disease. ${ }^{5,16}$ Periodontitis leads to worsening of lipid metabolism. Likewise, periodontal inflammation is related with the worsening of a hyperlipidaemic state by increasing the gingival crevicular fluid and proinflammatory cytokines. ${ }^{18}$ In a study conducted to assess the effect of improved periodontal health following periodontal treatment on metabolic lipid control of patients on anti-lipemic treatment, it was seen that enhanced periodontal health can affect metabolic control of hyperlipidemia and can be considered as an adjunct to the measures of hyperlipidemic patient care which are standardly used. ${ }^{18}$ Hence, statin as an adjunct to SRP may play a role in management of $\mathrm{CP}$ as well as hyperlipidemia.

Comparing systemic regimen with local delivery, the latter may offer essential benefits in terms of few adverse reactions and better patient compliance, as stated in the previous study. ${ }^{19}$

\section{CONCLUSION}

This study demonstrates that locally delivered gel of 1.2\% SMV into periodontal pockets, periodontitis patients stimulates a substantial benefits in the PD reduction, Clinical attachment gain as opposed to placebo gel as an adjunctive measure to SRP. Hence this will take periodontal healing in patients at risk for periodontal destruction in a new direction. Nevertheless, long-term, multicentre randomized, controlled clinical trials are necessary to establish the clinical, histological, and radiographical consequence on bone formation in those affected by chronic periodontitis.

\section{REFERENCES}

1. Laine ML, Crielaard W, Loos BG. Genetic susceptibility to periodontitis. Periodontol. 2000 2012;58:37-68. 
2. Blake GJ, Ridker PM. Are statins anti-inflammatory? Curr Control Trials Cardiovasc Med. 2000;1:161-5.

3. Kirmizis D, Chatzidimitriou D. Pleiotropic vasoprotective effects of statins: the chicken or the egg? Drug Des Dev Ther. 2009;3:191-204.

4. Shishehbor MH, Brennan ML, Aviles RJ, et al. Statins promote potent systemic antioxidant effects through specific inflammatory pathways. Circulation 2003;108:426-431.

5. Davignon J. Beneficial cardiovascular pleiotropic effects of statins. Circulation 2004;109:III39-43.

6. Laufs U, Liao JK. Isoprenoid metabolism and the pleiotropic effects of statins. Curr Atheroscler Rep. 2003;5:372-8.

7. Nagashima H, Aoka Y, Sakomura Y, et al. A 3hydroxy-3-methylglutaryl coenzyme A reductase inhibitor, cerivastatin, suppresses production of matrix metalloproteinase-9 in human abdoabdominal aortic aneurysm wall. J Vasc Surg. 2002;36:158-163.

8. Ohnaka K, Shimoda S, Nawata H, et al. Pitavastatin enhanced BMP-2 and osteocalcin expression by inhibition of Rho-associated kinase in human osteoblasts. Biochem Biophys Res Commun. 2001;287:337-342.

9. Mundy G, Garrett R, Harris S, et al. Stimulation of bone formation in vitro and in rodents by statins. Science 1999; 286:1946-9.

10. Lindy O, Suomalainen K, Makela M, Lindy S. Statin use is associated with fewer periodontal lesions: a retrospective study. BMC Oral Health 2008;8:16.

11. Sakoda K, Yamamoto M, Negishi Y, Liao JK, Node K,Izumi Y. Simvastatin decreases IL-6 and IL-8 production in epithelial cells. J Dent Res. 2006;85:520523.

12. Pradeep AR, Thorat MS. Clinical effect of subgingivally delivered simvastatin in the treatment of patients with chronic periodontitis: a randomized clinical trial. J Periodontol. 2010;81:214-22.

13. Pradeep AR, Priyanka N, Kalra N, Naik SB, Singh SP, Martande S. Clinical efficacy of subgingivally delivered 1.2-mg simvastatin in the treatment of individuals with class II furcation defects: a randomized controlled clinical trial. J Periodontol. 2012;83:1472-9.

14. Rao NS, Pradeep AR, Bajaj P, Kumari M, Naik SB. Simvastatin local drug delivery in smokers with chronic periodontitis: a randomized controlled clinical trial. Aust Dent J. 2013;58:156-62.

15. Fento_gluO", Bozkurt FY. The bi-directional relationship between periodontal disease and hyperlipidemia. Eur J Dent. 2008;2:142-146.

16.Takemoto M, Liao JK. Pleiotropic effects of 3hydroxy-3-methylglutaryl coenzyme a reductase inhibitors. Arterioscler Thromb Vasc Biol. 2001;21:17121719 .

17. Fento_glu O", Ko“ro_glu BK, Hicxyılmaz H, et al. Proinflammatory cytokine levels in association between periodontal disease and hyperlipidaemia. J Clin Periodontol. 2011;38:8-19.

18. Fento_glu O, So"zen T, Oz SG, et al. Short-term effects of periodontal therapy as an adjunct to antilipemic treatment. Oral Dis. 2010;16:648-54.

19. Sharma A, Pradeep AR. Clinical efficacy of $1 \%$ alendronate gel as local drug delivery system in the treatment of chronic periodontitis - A Randomized Controlled Clinical Trial. J Periodontol. 2012;83:11-8.

Cite this article as:

Gupta N, Verma S, Sharma S, Gill JS, Khurana A, Gupta S, Ul-Nisa T, Dewan A.

Effectiveness Of $1.2 \%$ Simvastatin Gel as an Adjunct to Non-Surgical Therapy in The Treatment of Chronic Periodontitis: A Split Mouth Randomized Controlled Trial. Int Healthc Res J. 2021;4(12)OR1-OR6 https://doi.org/10.26440/IHRJ/0412.03396

\section{AUTHOR AFFILIATIONS: (*Corresponding Author)}

1. Postgraduate Student, Department of Periodontics, I.T.S Dental College, Hospital \& Research Centre, Greater Noida [(https://orcid.org/oooo-0oo3-4854-3023, Neetika Gupta), (https://orcid.org/oooo-0oo1-9416-4134, Tauqeer-ul-Nisa), (https://orcid.org/oooo-0oo1-8591-0545, Arushi Dewan)]

2. Junior Resident, K.D. Dental College, Hospital \& Research Centre, Mathura (https://orcid.org/oooo-0oo3-4082-09377)

3. Junior Resident, I.T.S Dental College, Hospital \& Research Centre, Greater Noida [(https://orcid.org/oooo-ooo1-7558-o968,

Siddharth Sharma), (https://orcid.org/oooo-0oo2-1185-236X, Jaipreet Singh Gill)]

4. Graduate student, I.T.S Dental College, Hospital \&Research Centre, Greater Noida (https://orcid.org/oooo-0oo2-o746-7135)

5. Assistant Professor, Department of Periodontology, School of Dental Sciences, Sharda University, Greater Noida

(https://orcid.org/oooo-0oo1-8495-8723) 